\title{
Effect of Trelagliptin on Quality of Life in Patients with Type 2 Diabetes Mellitus: Study Protocol
}

Hitoshi Ishii · Yuki Suzaki · Yuko Miyata

Received: August 16, 2017 / Published online: October 26, 2017

(C) The Author(s) 2017. This article is an open access publication

\section{ABSTRACT}

Introduction: Long-term glycemic control in type 2 diabetes is critical to prevent or delay the onset of macrovascular and microvascular complications. Medication adherence is an integral component of type 2 diabetes management. Minimizing the dosing frequency of antidiabetic drugs may reduce treatment burden for patients and improve medication adherence. This study has been proposed to assess the reduction in treatment burden during 12 weeks' administration of trelagliptin, a weekly dosing dipeptidyl peptidase-4 (DPP-4) inhibitor, compared with a daily dosing DPP-4 inhibitor in patients with type 2 diabetes.

Methods: This is a multicenter, randomized, open-label, parallel-group, comparative study to be conducted at approximately 15 sites across

Enhanced content To view enhanced content for this article go to http://www.medengine.com/Redeem/ 83CCF060114FA8D1.

H. Ishii $(\bowtie)$

Department of Diabetology, Nara Medical

University, Kashihara, Nara, Japan

e-mail: hit3910@gmail.com

Y. Suzaki · Y. Miyata

Japan Medical Affairs, Takeda Pharmaceutical

Company Limited, Tokyo, Japan
Japan. A total of 240 patients are to be randomized 1:1 to receive trelagliptin or a daily DPP-4 inhibitor for 12 weeks. Efficacy and safety will be compared between the two groups. The primary endpoint is the change in total score for all items of the diabetes-therapy-related QOL questionnaire from treatment start to treatment end. The study will be conducted with the highest respect for the individual participants in accordance with the protocol, the Declaration of Helsinki, the Ethical Guidelines for Clinical Research, the ICH Consolidated Guideline for Good Clinical Practice, and applicable local laws and regulations.

Funding: Takeda Pharmaceutical Company Limited.

Trial registration number: Japic CTI-173482.

Keywords: Adherence; DPP-4 inhibitors; Quality of life; Treatment satisfaction; Trelagliptin

\section{INTRODUCTION}

Type 2 diabetes mellitus currently constitutes an enormous global burden and annual prevalence rates continue to rise [1]. At present, an estimated $12 \%$ of the total health expenditure worldwide is directed towards this largely preventable disease [1]. Treatment of individuals with type 2 diabetes aims to achieve a normal lifespan and a quality of life (QOL) similar to 
that of persons without diabetes [2]. Long-term glycemic control is critical to prevent or delay the onset of macrovascular and microvascular complications and their associated consequences for patients' health and health-related QOL [2].

Medication adherence is an integral component of type 2 diabetes management; however, treatment discontinuation during the early stages of the disease is not uncommon because patients are unaware of (or choose to ignore) their condition due to limited subjective symptoms or a low incidence of complications. Auto-recording systems for drug administration suggest that compliance difficulties increase with dosing frequency [3]. In this context, minimizing dosing frequency may increase treatment satisfaction and eliminate a major barrier to treatment continuation.

Dipeptidyl peptidase 4 (DPP-4) inhibitors are a newer class of oral antidiabetic agent with longer-lasting glycemic control compared with conventional therapies [4]. These agents are increasingly being positioned higher in treatment algorithms for type 2 diabetes [5]. Several daily dosing DPP-4 inhibitors are available in Japan for administration once or twice daily [2]. The first weekly dosing DPP-4 inhibitor, trelagliptin, was launched in Japan in 2015. Owing to its convenient once-weekly dosing schedule, trelagliptin has the potential to improve medication adherence, especially in patients newly starting oral glucose-lowering monotherapy [4].

The availability of an antidiabetic medication with a reduced treatment burden may be conducive to patients continuing with treatment. Accordingly, this study has been proposed to assess treatment burden during treatment with weekly trelagliptin or a daily DPP-4 inhibitor in patients with type 2 diabetes beginning oral antidiabetic therapy.

The objective of the study is to evaluate the reduction in treatment burden during administration for 12 weeks of once-weekly trelagliptin compared with a daily DPP-4 inhibitor in Japanese patients with type 2 diabetes newly starting oral glucose-lowering monotherapy, by measuring their treatment-related QOL.

\section{METHODS}

\section{Study Design}

This is a multicenter, randomized, open-label, parallel-group, comparative study to be conducted at approximately 15 study sites across Japan. The study is registered at Japan Pharmaceutical Information Center Clinical Trials Information: Japic CTI-173482.

\section{Inclusion Criteria}

Study subject eligibility is to be determined in accordance with the following criteria:

1. Outpatients with a diagnosis of type 2 diabetes.

2. Patients who have been maintained on a stable diet and exercise therapy only for at least 12 weeks prior to the start of screening.

3. Patients who require treatment with a DPP-4 inhibitor.

4. Patients with $\mathrm{HbA} 1 \mathrm{c} \geq 6.5 \%$ and $<10.0 \%$ at the start of screening.

5. Patients who completed the DTR-QOL questionnaire at the start of the screening period.

6. Patients who are receiving less than two types of medication for treatment of comorbidities (e.g., hypertension or dyslipidemia) at the start of screening.

7. Patients who, in the opinion of the investigators, are capable of understanding the content of the clinical study and complying with the study protocol requirements.

8. Patients who are willing and able to provide written informed consent prior to the initiation of any study procedures.

9. Patients aged $\geq 20$ years at the time of informed consent.

Female subjects of childbearing potential will be required to use adequate contraception from the time of signing informed consent throughout the study period.

\section{Exclusion Criteria}

Study subjects meeting any of the following criteria will not be included in this study: 
1. Patients under treatment with trelagliptin for type 2 diabetes at the start of screening.

2. Patients with a diagnosis of type 1 diabetes.

3. Patients with severe renal impairment or renal failure (e.g., eGFR $<30 \mathrm{~mL} / \mathrm{min} /$ $1.73 \mathrm{~m}^{2}$ or on dialysis).

4. Patients with serious heart disease or a cerebrovascular disorder, or a serious pancreatic, blood, or other disease.

5. Patients with a history of gastrointestinal resection.

6. Patients with a proliferative diabetic retinopathy.

7. Patients with malignancy.

8. Patients with a history of hypersensitivity or allergy to DPP-4 inhibitors.

9. Patients who are pregnant, breast-feeding, possibly pregnant, or planning to become pregnant.

10. Patients who may need to add or discontinue concomitant medication or change the dose during the study period.

11. Patients who will require treatment with a prohibited concomitant medication during the study period.

12. Patients participating in other clinical studies.

13. Patients assessed as ineligible for any other reason by the investigators.

\section{Randomization and Treatment}

Via the case registration web system, eligible subjects are to be randomized in a 1:1 ratio to receive trelagliptin $100 \mathrm{mg}$ [or $50 \mathrm{mg}$ in the case of moderate renal impairment (creatinine clearance $30 \leq 50 \mathrm{~mL} / \mathrm{min}$ )] once weekly or a daily DPP-4 inhibitor (alogliptin, anagliptin, linagliptin, saxagliptin, sitagliptin, teneligliptin, or vildagliptin) at the dosage and administration recommended in the package inserts. For the purpose of adjusting the effects of the reduction in diabetes treatment burden, subjects will be randomized using their HbA1c level $(<8.0 \%$ or $\geq 8.0 \%)$ and the total score for all factors of the Diabetes Therapy-Related QOL (DTR-QOL) questionnaire $[<80 \quad(168.2$ as a score) or $\geq 80$ ( $\geq 168.2$ as a score)] at the start of screening as stratification factors. The DTR-QOL questionnaire uses a scale of $1-7$ ( $7=$ best) for each of its 29 questions. The total score is calculated by adding the scores for all questions and the sum is converted to 0-100 [i.e. best score $(203)=100$; worst score $(29)=0$ ] [6].

Use of diabetic medications other than the allocated study medication is prohibited from the start of screening to the end of treatment. In principle, concomitant medications cannot be added or withdrawn or dosages changed during the clinical study period unless considered necessary by study investigators.

\section{Study Procedure}

The evaluation period is 16 weeks, consisting of a 4-week screening period and a 12 -week treatment period (Fig. 1). Subjects are to visit their corresponding study site four times during the course of the study: at the start of screening (visit $1,-4$ weeks), at the start of treatment (visit 2, week 0 ), during treatment (visit 3 , week 4 ), and at the end of treatment (visit 4 , week 12). The 12-week study duration is considered to be an appropriate length of time to evaluate treatment response with oral antidiabetic medications [2], and possibly also to evaluate changes in diabetes therapy-related QOL as patients become accustomed to treatment practice.

Assessments are to be performed according to the schedule for study procedures (Table 1). The investigator will observe and assess each participant from the time of informed consent through to treatment completion or discontinuation (until 14 days after the last dose of study medication). All examinations, observations, and evaluations are to be performed by the investigator at the designated time points.

Subjects' participation in the study may be discontinued at the investigator's discretion in the event of any of the following conditions: adverse event requiring withdrawal, major protocol deviation, loss to follow-up, voluntary withdrawal, study termination, pregnancy, lack of efficacy, or for any other reason which the investigator deems discontinuation to be necessary. Individual subjects may discontinue 


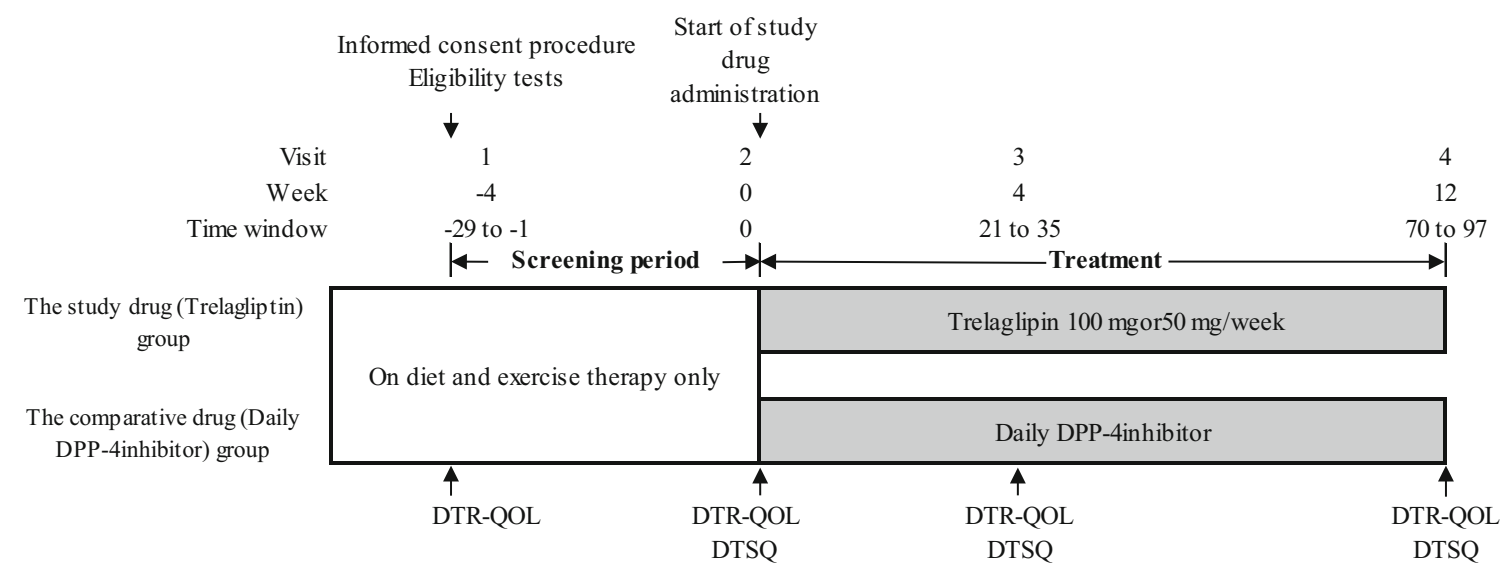

Fig. 1 Schematic of the study design. DPP-4 dipeptidyl peptidase 4, DTR-QOL Diabetes Therapy-Related Quality of Life questionnaire, DTSQ Diabetes Treatment Satisfaction questionnaire

participation at any time during the study without providing a reason.

\section{Efficacy Endpoints}

The primary endpoint is the change in total score for all items (29 questions) of the DTR-QOL questionnaire from treatment start (week 0) to treatment end (week 12).

Secondary efficacy variables are:

- Change in total score for each factor of the DTR-QOL questionnaire [factor 1: burden on social activities and daily activities (13 questions); factor 2: anxiety and dissatisfaction with treatment (8 questions); factor 3: hypoglycemia (4 questions); factor 4: treatment satisfaction (4 questions)] at each assessment time point.

- Change in total score for all questions of the DTR-QOL questionnaire at each assessment time point.

- Change in total score for items of the Diabetes Treatment Satisfaction questionnaire (DTSQ; 6 questions on treatment satisfaction, excepting 2 items for blood glucose control) $[7,8]$ at each assessment time point.

- Change in total score for all questions of the DTR-QOL questionnaire and all items of the DTSQ (for treatment satisfaction) stratified by the following factors at the start of treatment:
- Use of medication for treatment of comorbidities

- Number of daily doses for treatment of comorbidities ( $<2$ or $\geq 2$ times)

- Total number of daily tablets for treatment of comorbidities ( $<2$ or $\geq 2$ tablets)

- Number of daily doses of study drug or comparative drug (once weekly, once daily, twice daily).

- Change in score for each question of the DTR-QOL questionnaire at each assessment time point.

- Change in score for each (treatment satisfaction) question of the DTSQ at each assessment time point.

\section{Safety Endpoints}

Safety is to be assessed according to adverse events, incidence of hypoglycemia, and duration and number of hospitalizations for type 2 diabetes, excluding hospitalizations for a type 2 diabetes education program.

\section{Other Endpoints}

Laboratory tests are to be performed under $\geq 10 \mathrm{~h}$ fasting state conditions and in accordance with the schedule provided in Table 1. Tests include: HbA1c, fasting blood glucose, fasting insulin, fasting glucagon, glycoalbumin, $1,5-A G$, serum creatinine, urinary $8-\mathrm{OHdG}$ 
Table 1 Schedule for study procedures

\begin{tabular}{|c|c|c|c|c|c|}
\hline \multirow[t]{2}{*}{ Visit time } & \multirow{2}{*}{$\begin{array}{l}\text { Observation period } \\
-4\end{array}$} & \multicolumn{3}{|c|}{ Treatment period } & \multirow[t]{2}{*}{ Discontinuation } \\
\hline & & $\mathbf{0}$ & 4 & 12 & \\
\hline Time window (days) & -29 to -1 & 0 & $21-35$ & $70-97$ & Until 14 days after last dose \\
\hline Visit number & 1 & 2 & 3 & 4 & \\
\hline Informed consent procedure & $\mathrm{X}$ & & & & \\
\hline Inclusion/exclusion criteria & $\mathrm{X}$ & $\mathrm{X}$ & & & \\
\hline Demographic data, previous history & $\mathrm{X}$ & & & & \\
\hline Medical examination & $\mathrm{X}$ & $\mathrm{X}$ & $\mathrm{X}$ & $\mathrm{X}$ & $\mathrm{X}$ \\
\hline Height & $\mathrm{X}$ & & & & \\
\hline Weight & $\mathrm{X}$ & $\mathrm{X}$ & $\mathrm{X}$ & $\mathrm{X}$ & $\mathrm{X}$ \\
\hline BMI & $\mathrm{X}$ & & & & \\
\hline Vital signs & $\mathrm{X}$ & $\mathrm{X}$ & $\mathrm{X}$ & $\mathrm{X}$ & $\mathrm{X}$ \\
\hline Concomitant medications & $\mathrm{X}$ & $\mathrm{X}$ & $\mathrm{X}$ & $\mathrm{X}$ & $\mathrm{X}$ \\
\hline Concurrent medical conditions & $\mathrm{X}$ & $\mathrm{X}$ & & & \\
\hline \multicolumn{6}{|l|}{ Laboratory tests } \\
\hline Blood chemistry & $\mathrm{X}$ & $\mathrm{X}$ & $\mathrm{X}$ & $\mathrm{X}$ & $\mathrm{X}$ \\
\hline Urinalysis & $\mathrm{X}$ & $\mathrm{X}$ & $\mathrm{X}$ & $\mathrm{X}$ & $\mathrm{X}$ \\
\hline $\begin{array}{l}\text { Drug dispensation (study } \\
\text { drug/comparator drug) }\end{array}$ & & $\mathrm{X}$ & $\mathrm{X}$ & & \\
\hline Treatment adherence & & $\mathrm{X}$ & $\mathrm{X}$ & $\mathrm{X}$ & $\mathrm{X}$ \\
\hline $\begin{array}{l}\text { Basic Information on Study Subject (Your } \\
\text { Basic Profile) }\end{array}$ & $\mathrm{X}$ & $\mathrm{X}$ & $\mathrm{X}$ & $\mathrm{X}$ & $\mathrm{X}$ \\
\hline DTSQ & & $\mathrm{X}$ & $\mathrm{X}$ & $\mathrm{X}$ & $\mathrm{X}$ \\
\hline DTR-QOL & $\mathrm{X}$ & $\mathrm{X}$ & $\mathrm{X}$ & $\mathrm{X}$ & $\mathrm{X}$ \\
\hline Adverse events evaluation & & $X \rightarrow$ & $\leftarrow X \rightarrow$ & $\leftarrow X$ & $\leftarrow X$ \\
\hline Incidence of hypoglycemia & & $X \rightarrow$ & $\leftarrow X \rightarrow$ & $\leftarrow X$ & $\leftarrow \mathrm{X}$ \\
\hline Hospitalization for type 2 diabetes & & $X \rightarrow$ & $\leftarrow X \rightarrow$ & $\leftarrow X$ & $\leftarrow X$ \\
\hline
\end{tabular}

BMI body mass index, DTSQ Diabetes Treatment Satisfaction questionnaire, DTR-QOL Diabetes Therapy-Related Quality of Life questionnaire

[using a correction value of uric creatinine (8-OHdG/creatinine)], and urinary creatinine.

Treatment adherence will be checked at week 4 and week 12 of the treatment period (Table 1).
Study subjects are to complete the Your Basic Profile component of the Basic Information on Study Subject form with respect to their diabetes therapy at each assessment time point during the screening period and treatment 
period (Table 1). Details of the Your Basic Profile questionnaire are provided in Fig. 2 .

\section{Data Collection}

Demographic data to be collected include date of birth, gender, height, weight, body mass index, smoking history, alcohol intake history, and time (month and year) of diabetes onset (or diabetes diagnosis).

Medical history is to include information on clinically problematic diseases and symptoms either resolved or recovered within a year before the start of the screening period.

Any continuous disease or symptom observed at screening until before the start of study treatment will be regarded as a comorbidity.

\section{Physical Examination}

The presence/absence of clinically significant abnormalities at subsequent physical examinations during the course of treatment will be determined by comparison with the baseline physical examination.

\section{Concomitant Medication}

Use of concomitant medications (name, dosage, route of administration, duration, intended use), either prescribed by physicians or over-the-counter medicines purchased by study subjects, will be investigated and recorded at each visit from start of screening to study completion. Also recorded will be: use of therapeutic drugs for comorbidities; number of daily doses of drugs, including therapeutic drugs for comorbidities ( $<2$ times or $\geq 2$ times); and total number of daily tablets of drugs, including therapeutic drugs for comorbidities ( $<2$ tablets or $\geq 2$ tablets), from the start of screening to study completion.

\section{Adverse Events}

Adverse events, including adverse events of special interest to DPP-4 inhibitors as per product labels, are to be collected from the start of treatment to the end of the treatment period (or discontinuation). Any adverse event will be assessed with respect to its name, seriousness, severity, causal relationship to study medication, causal relationship with study procedures, date of onset, date of resolution, actions taken, and outcome.

Adverse events, medical history, and comorbidities will be coded using the Medical Dictionary for Regulatory Activities (MedDRA).

\section{Treatment Adherence}

Subjects are to be instructed to record study drug or comparative drug usage on a Diabetes Treatment Medication Record Card by pressing a button at the time the medication is taken. The card's electronic circuit board will record the time(s) of day that the medication is taken. Subjects will be instructed to bring any leftover medication and empty sheets at each visit to allow adherence and usage to be checked along with the Diabetes Treatment Medication Record Card.

\section{Statistical Methods}

Two analysis sets have been defined for the study. The full analysis set (FAS) includes all randomized subjects who receive at least one dose of trelagliptin or a daily DPP-4 inhibitor. The safety population includes subjects who receive at least one dose of trelagliptin or a daily DPP-4 inhibitor.

Efficacy endpoints will be analyzed in the FAS. For the primary endpoint, comparison between treatment groups is to be conducted using the analysis of covariance (ANCOVA) model, including: change in total score for all items of the DTR-QOL questionnaire from treatment start to treatment end (week 0 to week 12) as a dependent variable; total score of the DTR-QOL questionnaire $(<80$ or $\geq 80)$ and HbA1c $(<8.0 \%$ or $\geq 8.0 \%)$ at the start of the screening period as covariates; treatment group as an independent variable. The level of significance is $5 \%$ (two-sided).

For the secondary endpoints of change in total score for each factor of the DTR-QOL 


\section{Your Basic Profile (VISIT1)}

Please answer the following questions by circling the applicable number for each question.

1) How well was your blood glucose level controlled for the past one month?

\begin{tabular}{|c|c|c|c|c|}
\hline $\begin{array}{c}\text { Well- } \\
\text { controlled }\end{array}$ & \multicolumn{2}{|c|}{ Not sure } & $\begin{array}{c}\text { Poorly- } \\
\text { controlled }\end{array}$ \\
\hline 1 & 2 & 3 & 4 & 5 \\
\hline
\end{tabular}

2) Which type of medication would you like to use to treat your diabetes assuming that 2) benefits, side effects and daily costs are the same?

\begin{tabular}{|c|c|c|c|c|c|}
\hline 3 times daily & Twice daily & Once daily & $\begin{array}{c}\text { Once a } \\
\text { week }\end{array}$ & $\begin{array}{c}\text { Any would } \\
\text { be OK }\end{array}$ \\
\hline 1 & 2 & 3 & 4 & 5 \\
\hline
\end{tabular}

\section{Your Basic Profile (VISIT2)}

Please answer the following questions by circling the applicable number for each question.

1) How well was your blood glucose level controlled for the past one month?

\begin{tabular}{|c|c|c|c|c|}
$\begin{array}{c}\text { Well- } \\
\text { controlled }\end{array}$ & \multicolumn{3}{c}{ Not sure } & $\begin{array}{c}\text { Poorly- } \\
\text { controlled }\end{array}$ \\
\hline 1 & 2 & 3 & 4 & 5 \\
\hline
\end{tabular}

2) Have you experienced hypoglycemia (i.e. too-low blood glucose) for the past one month? \begin{tabular}{|l|l|}
\hline 1 & Yes-Please provide the frequency: ( ) times \\
\hline 2 & No \\
\hline
\end{tabular}

3) When did you take your medication(s) for conditions other than diabetes (e.g. hypertension) 3) for the past one month?

$$
\begin{array}{|c|c|c|c|c|c|}
\text { At breakfast } & \text { At lunch } & \text { At dinner } & \text { At bedtime } & \begin{array}{c}
\text { No particular } \\
\text { rules }
\end{array} & \text { Not taking } \\
\hline 1 & 2 & 3 & 4 & 5 & 6 \\
\hline
\end{array}
$$

4) How often did you forget to take your medication(s) for conditions other than diabetes (e.g. 4) hypertension) for the past one month?

\begin{tabular}{|c|c|c|c|c|c|c|}
\hline Never & Rarely & $\begin{array}{c}1-3 \text { times } \\
\text { per month }\end{array}$ & $\begin{array}{c}\text { Once a } \\
\text { week }\end{array}$ & $\begin{array}{c}\text { A few times } \\
\text { a week }\end{array}$ & $\begin{array}{c}>4 \text { times a } \\
\text { week }\end{array}$ & Not taking \\
\hline 1 & 2 & 3 & 4 & 5 & 6 & 7 \\
\hline
\end{tabular}

5) What type of job do you have?

\begin{tabular}{|c|c|c|c|}
$\begin{array}{c}\text { Full time } \\
\text { job* }\end{array}$ & $\begin{array}{c}\text { Part time } \\
\text { job }\end{array}$ & No job & Other \\
\hline 1 & 2 & 3 & 4 \\
\hline
\end{tabular}

"At work almost all day: company employee, self-ow ned business, etc.

6) How many days each week do you go to work (or go out) in the morning?

\begin{tabular}{|c|c|c|c|c|}
\hline Rarely & $\begin{array}{c}1-2 \text { days per } \\
\text { week }\end{array}$ & $\begin{array}{c}\text { 3-4 days per } \\
\text { week }\end{array}$ & $\begin{array}{c}\text { 5-6 days per } \\
\text { week }\end{array}$ & $\begin{array}{l}7 \text { days per } \\
\text { week }\end{array}$ \\
\hline 1 & 2 & 3 & 4 & 5 \\
\hline
\end{tabular}

7) When you go to work (or go out) in the morning, how long does it take from the time you wake up until you leave home?

More than 1 More than 2

Less than $1 \mathrm{hi}$ hr but less hr but less More than $3 \mathrm{hr}$

\begin{tabular}{|l|c|c|c|}
\hline 1 & than $2 \mathrm{hr}$ & than $3 \mathrm{hr}$ & \\
\hline 1 & 2 & 3 & 4 \\
\hline
\end{tabular}

Fig. 2 Your Basic Profile component of the Basic Information on Study Subject form. Visit 1 to visit 4 


\section{Your Basic Profile (VISIT3)}

Please answer the following questions by circling the applicable number for each question.

1) How well was your blood glucose level controlled for the past one month?

\begin{tabular}{|c|c|c|c|c|}
$\begin{array}{c}\text { Well- } \\
\text { controlled }\end{array}$ & \multicolumn{3}{c}{ Not sure } & $\begin{array}{c}\text { Poorly- } \\
\text { controlled }\end{array}$ \\
\hline 1 & 2 & 3 & 4 & 5 \\
\hline
\end{tabular}

2) Have you experienced hypoglycemia (i.e. too-low blood glucose) for the past one month?

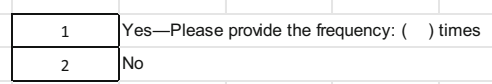

3) When did you take your diabetes medication(s) for the past one month?

\begin{tabular}{|c|c|c|c|c|c|}
\hline At breakfast & At lunch & At dinner & At bedtime & $\begin{array}{c}\text { No particular } \\
\text { rules }\end{array}$ & Not taking \\
\hline 1 & 2 & 3 & 4 & 5 & 6 \\
\hline
\end{tabular}

4) When did you take your medication(s) for conditions other than diabetes (e.g. hypertension) for the past one month?

\begin{tabular}{|c|c|c|c|c|c|} 
At breakfast & At lunch & At dinner & At bedtime & $\begin{array}{c}\text { No particular } \\
\text { rules }\end{array}$ & Not taking \\
\hline 1 & 2 & 3 & 4 & 5 & 6 \\
\hline
\end{tabular}

5) How often did you have to take your medication(s) during your busy hours for the past one month?

\begin{tabular}{|c|c|c|c|c|}
\hline Always & Sometimes & Occasionally & Rarely & Never \\
\hline 1 & 2 & 3 & 4 & 5 \\
\hline
\end{tabular}

6) How often did you forget to take your medication(s) for conditions other than diabetes (e.g. hypertension) for the past one month?

\begin{tabular}{|c|c|c|c|c|c|c|}
\hline Never & Rarely & $\begin{array}{c}1-3 \text { times } \\
\text { per month }\end{array}$ & $\begin{array}{c}\text { Once a } \\
\text { week }\end{array}$ & $\begin{array}{c}\text { A few times } \\
\text { a week }\end{array}$ & $\begin{array}{c}>4 \text { times a } \\
\text { week }\end{array}$ & Not taking \\
\hline 1 & 2 & 3 & 4 & 5 & 6 & 7 \\
\hline
\end{tabular}

7) How often did you forget to take your diabetes medication(s) for the past one month?

\begin{tabular}{|c|c|c|c|c|c|c|}
\hline Never & Rarely & $\begin{array}{c}1-3 \text { times } \\
\text { per month }\end{array}$ & $\begin{array}{c}\text { Once a } \\
\text { week }\end{array}$ & $\begin{array}{c}\text { A few times } \\
\text { a week }\end{array}$ & $\begin{array}{c}>4 \text { times a } \\
\text { week }\end{array}$ & Not taking \\
\hline 1 & 2 & 3 & 4 & 5 & 6 & 7 \\
\hline
\end{tabular}

\section{Your Basic Profile (VISIT3)}

Please answer how you felt when you were in the following situations for the past one month, by circling the number which best represents your feeling for each question.

1) I felt guilty when I forgot to take my diabetes medication(s).

\begin{tabular}{|c|c|c|c|c|}
\hline Exactly & \multicolumn{1}{c}{ Somewhat } & Not sure & Not exactly & Never \\
\hline 1 & 2 & 3 & 4 & 5 \\
\hline
\end{tabular}

2) It is burdensome to take my diabetes medication(s) when I'm going out, travelling, or on a business trip.

\begin{tabular}{|c|c|c|c|c|}
\hline Exactly & \multicolumn{1}{c}{ Somewhat } & Not sure & Not exactly & Never \\
\hline 1 & 2 & 3 & 4 & 5 \\
\hline
\end{tabular}

3) Which type of medication would you like to use to treat your diabetes assuming that benefits, side effects a) and daily costs are the same?

\begin{tabular}{|c|c|c|c|c|}
3 times daily & \multicolumn{1}{c}{ Twice daily } & Once daily & $\begin{array}{c}\text { Once a } \\
\text { week }\end{array}$ & $\begin{array}{c}\text { Any would } \\
\text { be OK }\end{array}$ \\
\hline 1 & 2 & 3 & 4 & 5 \\
\hline
\end{tabular}

Fig. 2 continued 
Your Basic Profile (VISIT4)

Please answer the following questions by circling the applicable number for each

1) How well was your blood glucose level controlled for the past one month?

\begin{tabular}{|c|c|c|c|c|}
$\begin{array}{c}\text { Well- } \\
\text { controlled }\end{array}$ & \multicolumn{2}{c}{ Not sure } & & $\begin{array}{c}\text { Poorly- } \\
\text { controlled }\end{array}$ \\
\hline 1 & 2 & 3 & 4 & 5 \\
\hline
\end{tabular}

2) Have you experienced hypoglycemia (i.e. too-low blood glucose) for the past one month? \begin{tabular}{|l|l|}
\hline 1 & Yes-Please provide the frequency: ( ) times \\
\hline 2 & No \\
\hline
\end{tabular}

3) When did you take your diabetes medication(s) for the past one month?

\begin{tabular}{|c|c|c|c|c|c|}
\hline At breakfast & At lunch & At dinner & At bedtime & $\begin{array}{c}\text { No particular } \\
\text { rules }\end{array}$ & Not taking \\
\hline 1 & 2 & 3 & 4 & 5 & 6 \\
\hline
\end{tabular}

4) When did you take your medication(s) for conditions other than diabetes (e.g. hypertension) 4) for the past one month?

\begin{tabular}{|c|c|c|c|c|c|}
\hline At breakfast & At lunch & At dinner & At bedtime & $\begin{array}{c}\text { No particular } \\
\text { rules }\end{array}$ & Not taking \\
\hline 1 & 2 & 3 & 4 & 5 & 6 \\
\hline
\end{tabular}
5) How often did you have to take your medication(s) during your busy hours for the past one
month?

\begin{tabular}{|c|c|c|c|c|}
\hline Always & \multicolumn{1}{c}{ Sometimes } & \multicolumn{1}{l}{ Occasionally } & Rarely & Never \\
\hline 1 & 2 & 3 & 4 & 5 \\
\hline
\end{tabular}

6) How often did you forget to take your medication(s) for conditions other than diabetes (e.g. 6) hypertension) for the past one month?

\begin{tabular}{|c|c|c|c|c|c|c|c|}
\hline Never & Rarely & $\begin{array}{c}1-3 \text { times } \\
\text { per month }\end{array}$ & $\begin{array}{c}\text { Once a } \\
\text { week }\end{array}$ & $\begin{array}{c}\text { A few times } \\
\text { a week }\end{array}$ & $\begin{array}{c}>4 \text { times a } \\
\text { week }\end{array}$ & Not taking \\
\hline 1 & 2 & 3 & 4 & 5 & 6 & 7 \\
\hline
\end{tabular}

7) How often did you forget to take your diabetes medication(s) for the past one month?

\begin{tabular}{|c|c|c|c|c|c|c|c|}
\hline Never & Rarely & $\begin{array}{c}1-3 \text { times } \\
\text { per month }\end{array}$ & $\begin{array}{c}\text { Once a } \\
\text { week }\end{array}$ & $\begin{array}{c}\text { A few times } \\
\text { a week }\end{array}$ & $\begin{array}{c}>4 \text { times a } \\
\text { week }\end{array}$ & Not taking \\
\hline 1 & 2 & 3 & 4 & 5 & 6 & 7 \\
\hline
\end{tabular}

\section{Your Basic Profile (VISIT4)}

Please answer how you felt when you were in the following situations for the past one month, by circling the number which best represents your feeling for each question.

1) I felt guilty when I forgot to take my diabetes medication(s).

\begin{tabular}{|c|c|c|c|c|}
\hline Exactly & Somewhat & Not sure & Not exactly & Never \\
\hline 1 & 2 & 3 & 4 & 5 \\
\hline
\end{tabular}
2) It is burdensome to take my diabetes medication(s) when I'm going out, travelling, or on a
business trip.

\begin{tabular}{|c|c|c|c|c|}
\hline Exactly & Somewhat & Not sure & Not exactly & Never \\
\hline 1 & 2 & 3 & 4 & 5 \\
\hline
\end{tabular}

$\begin{aligned} & \text { 3) Which type of medication would you like to use to treat your diabetes assuming that benefits, } \\
& \text { side effects and daily costs are the same? }\end{aligned}$
\begin{tabular}{|c|c|c|c|c|}
\hline times daily & Twice daily & Once daily & $\begin{array}{c}\text { Once a } \\
\text { week }\end{array}$ & $\begin{array}{c}\text { Any would } \\
\text { be OK }\end{array}$ \\
\hline 1 & 2 & 3 & 4 & 5 \\
\hline
\end{tabular}

Fig. 2 continued 
questionnaire at each assessment time point, change in total score for all questions of the DTR-QOL questionnaire at each assessment time point, and change in total score for all (treatment satisfaction) questions of the DTSQ at each assessment time point, summary statistics [number of patients, mean, standard deviation (SD), maximum, minimum, and quantile] and two-sided 95\% confidence intervals (CIs) for means per treatment group will be calculated to plot changes in means and SDs. Point estimates and two-sided 95\% CIs for differences between treatment groups will also be calculated. This same analysis will be performed for the change in mean from baseline (week 0) of each secondary efficacy variable.

The ANCOVA model described above for the primary endpoint will also be used to analyze total scores for each factor of the DTR-QOL questionnaire and the DTSQ.

With regard to other endpoints, summary statistics for measurements or changes from baseline (week 0) in laboratory tests will be calculated per treatment group. The treatment adherence of each study subject will be calculated and summary statistics per treatment group will be analyzed. Frequency of answers to each question of Your Basic Profile at each visit will be calculated and summary statistics per treatment group will be analyzed.

Safety endpoints will be analyzed in the safety population using frequency tables for incidences of adverse events, hypoglycemia, and hospitalizations for worsening type 2 diabetes per treatment group.

\section{Rationale for Planned Sample Size}

With respect to the primary endpoint-the change in total score from baseline to end of treatment for all questions of the DTR-QOL questionnaire, mean changes in the trelagliptin and daily DPP-4 inhibitor groups were assumed to be $19.0 \%$ and $14.4 \%$, respectively. The mean change in the trelagliptin group was assumed by reference to data from the validation trial of the DTR-QOL questionnaire [6], and the mean change in the daily DPP-4 inhibitor group was assumed by reference to data from previously conducted research on sodium glucose transporter 2 inhibitors [9]. The common SD was assumed to be $12.1 \%$ by reference to the latter data [9]. Using a 5\% significance level (twosided) for analysis of the primary endpoint, at least 110 subjects per group would be required to ensure $80 \%$ power for comparisons between the trelagliptin and daily DPP-4 inhibitor groups. Assuming a type 2 diabetes treatment discontinuation rate of $8 \%$ [based on results for Topic 2 of the Strategic Studies on the Prevention of Diabetes (JDOIT-2)] [10], the number of randomized subjects was established as 120 subjects per group, or 240 subjects in total.

\section{ACKNOWLEDGEMENTS}

Funding for this research and article processing charges were provided by Takeda Pharmaceutical Company Limited (Tokyo, Japan). The study sponsor, Takeda Pharmaceutical Company Limited, was involved in all stages of the study research and manuscript preparation. All authors participated in the design of the study, had access to the data, and contributed to the manuscript development. All authors vouch for the accuracy and completeness of the information provided, and all authors took the decision to submit the manuscript for publication. Hitoshi Ishii is the guarantor for the contents of this article. All named authors meet the International Committee of Medical Journal Editors (ICMJE) criteria for authorship for this manuscript, take responsibility for the integrity of the work as a whole, and have given final approval for the version to be published. Editorial assistance in the preparation of this manuscript was provided by Kerry Dechant of Content Ed Net, with funding from Takeda Pharmaceutical Company Limited.

Disclosures. Hitoshi Ishii has received lecture and/or consultant fees from Astellas Pharma Inc., AstraZeneca K.K., Boehringer Ingelheim, Daiichi Sankyo Company, Ltd., Eli Lilly Japan K.K., Kowa Pharmaceutical Co. Ltd., Kyowa Hakko Kirin Co. Ltd., Merck \& Co. Inc., Mitsubishi Tanabe Pharma Corporation, Novartis Pharma K.K., Novo Nordisk Pharma Ltd., Ono 
Pharmaceutical Co. Ltd., Sanofi K.K., Shionogi \& Co. Ltd., Sumitomo Dainippon Pharma, Takeda Pharmaceutical Company, Ltd., and Taisho Toyama Pharmaceutical Co. Ltd., outside the submitted work. Yuki Suzaki is a full-time employee of Takeda Pharmaceutical Company Limited. Yuko Miyata is a full-time employee of Takeda Pharmaceutical Company Limited.

Compliance with Ethics Guidelines. The study is to be conducted with the highest respect for the individual participants in accordance with the protocol. All procedures followed were in accordance with the ethical standards of the responsible committee on human experimentation (institutional and national) and with the Helsinki Declaration of 1964, as revised in 2013. Informed consent was obtained from all patients for being included in the study. The study is to be conducted following Ethical Guidelines for Clinical Research published by the Japanese Ministry of Education, Culture, Sports, Science and Technology and Ministry of Health, Labour and Welfare (2014 revision), the ICH Consolidated Guideline for Good Clinical Practice, and applicable local laws and regulations.

Study participants private/personal information will be protected throughout the study. Subjects' source data will be linked to the sponsor's database or related documentation using a study-specific, anonymized identification (ID) code. Limited information on study subjects such as gender, age, and date of birth may be used within the scope of all applicable laws and regulations to identify study subjects and confirm the accuracy of study subject ID codes.

Data Availability. Data sharing is not applicable to this article as it describes a study protocol.

Informed Consent. The investigator will provide an explanation of the study to each eligible participant, using the informed consent document. The investigator will complete a case report form for each subject who has signed the informed consent form.
Open Access. This article is distributed under the terms of the Creative Commons Attribution-NonCommercial 4.0 International License (http://creativecommons.org/licenses/ by-nc/4.0/), which permits any noncommercial use, distribution, and reproduction in any medium, provided you give appropriate credit to the original author(s) and the source, provide a link to the Creative Commons license, and indicate if changes were made.

\section{REFERENCES}

1. International Diabetes Federation. www.idf.org. Accessed 12 July 2017.

2. Japan Diabetes Society. Treatment guide for diabetes 2016-2017. Tokyo: Bunkodo; 2016.

3. Paes AH, Bakker A, Soe-Agnie CJ. Impact of dosage frequency on patient compliance. Diabetes Care. 1997;20(10):1512-7.

4. Kaku K. First novel once-weekly DPP-4 inhibitor, trelagliptin, for the treatment of type 2 diabetes mellitus. Expert Opin Pharmacother. 2015;16(16):2539-47.

5. Deacon CF, Lebovitz HE. Comparative review of dipeptidyl peptidase-4 inhibitors and sulphonylureas. Diabetes Obes Metab. 2016;18(4):333-47.

6. Ishii H. Development and psychometric validation of the Diabetes Therapy-Related QOL (DTR-QOL) questionnaire. J Med Econ. 2012;15(3):556-63.

7. Bradley C. Diabetes treatment satisfaction questionnaire. In: Bradley C, editor. Handbook of psychology and diabetes: a guide to psychological measurement in diabetes research and practice. Chur: Harwood Academic; 1994. p. 111-32.

8. Ishii H, Bradley C, Riazi A, Barendse S, Yamamoto T. The Japanese version of the diabetes treatment satisfaction questionnaire (DTSQ): translation and clinical evaluation. J Clin Exp Med. 2000;192:809-14 (In Japanese).

9. Yamazaki M, Higo N, Kaneko T, et al. SGLT2 inhibitors as the trigger for diabetes care: reconfirmed importance of behavior modification after drug administration. J Japan Diab Soc. 2015;58:745-52 (In Japanese).

10. Izumi K, Noda M. In order to reduce the interruption of diabetes treatment. Diabetes Frontier. 2014;25:709-18 (In Japanese). 